\title{
Como identificar uma manifestação oral de Herpes-Zoster?
}

\author{
How to identify a oral manifestation of Herpes-Zoster? \\ ¿Cómo identificar una manifestación oral herpes-zoster?
}

Recebido: 02/02/2021 | Revisado: 07/02/2021 | Aceito: 09/02/2021 | Publicado: 17/02/2021

Fernanda Guimarães

ORCID: https://orcid.org/0000-0001-5030-0392

Universidade Estadual do Oeste do Paraná, Brasil

E-mail: fguimaraes168@gmail.com

Mateus Diego Pavelski

ORCID: https://orcid.org/0000-0002-1691-390X

Universidade Estadual Paulista Júlio de Mesquita Filho, Brasil

E-mail: mateus_pavelski@hotmail.com

Eduardo Dallazen

ORCID: https://orcid.org/0000-0002-7994-5634

Universidade Estadual Paulista Júlio de Mesquita Filho, Brasil

E-mail: eduardo.dallazen@unesp.br

Anderson Maikon de Souza Santos

ORCID: https://orcid.org/0000-0001-9371-9417

Universidade Estadual Paulista Júlio de Mesquita Filho, Brasil

E-mail: ams.santos@unesp.br

Leonardo Alan Delanora

ORCID: https://orcid.org/0000-0002-3002-4420

Universidade Estadual Paulista Júlio de Mesquita Filho, Brasil

E-mail: Leonardo.delanora@unesp.br

William Phillip Pereira da Silva

ORCID: https://orcid.org/0000-0003-4172-7217

Universidade Estadual Paulista Júlio de Mesquita Filho, Brasil E-mail: william_phillip@hotmail.com

Leonardo Perez Faverani

ORCID: https://orcid.org/0000-0003-2249-3048

Universidade Estadual Paulista Júlio de Mesquita Filho, Brasil E-mail: Leonardo.faverani@unesp.br

Osvaldo Magro Filho

ORCID: https://orcid.org/0000-0002-9821-2479

Universidade Estadual Paulista Júlio de Mesquita Filho, Brasil

E-mail: Osvaldo.magro@unesp.br

\begin{abstract}
Resumo
O herpes-zóster é uma infecção viral causada pela reativação do vírus da varicela-zóster, que acomete geralmente a população idosa. $\mathrm{O}$ vírus da varicela, quando em estado dormente, se localiza nos gânglios trigeminais e quando reativado pode causar lesões no rosto e vesículas intra bucais. Esta doença pode afetar com maior prevalência pacientes imunossuprimidos e caracteriza-se por erupções maculopapulares distribuídas na região do nervo afetado, causando dores intensas, tremores e até parestesia. O diagnóstico do herpes zoster geralmente é estabelecido por meio do quadro clínico apresentado pelo paciente e o tratamento é voltado aos sintomas e à causa, optando pelo uso de medicações antivirais sistêmicas e tópicas. Este artigo relata o caso de uma paciente, do sexo feminino, leucoderma, sem problemas de saúde e tratamentos imunossupressores prévios, de 56 anos de idade, que deu entrada ao pronto socorro, tendo com queixa principal a dor extra oral em hemiface direita, com evolução rápida de três dias após exodontia.
\end{abstract}

Palavras-chave: Herpes Zoster; Boca; Medicina bucal.

\begin{abstract}
Herpes zoster is a viral infection caused by the reactivation of the varicella-zoster virus, which generally affects the elderly population. The varicella virus, when in a dormant state, is located in the trigeminal ganglia and when reactivated can cause lesions on the face and intraoral vesicles. This disease can affect immunosuppressed patients with greater prevalence and is characterized by maculopapular eruptions distributed in the region of the affected nerve, causing severe pain, tremors and even paresthesia. The diagnosis of herpes zoster is usually established through the clinical picture presented by the patient and the treatment is focused on the symptoms and the cause, opting for the use of systemic and topical antiviral medications. This article reports the case of a female patient, caucasian, without health problems and previous immunosuppressive treatments, 56 years old, who came to the emergency room, with the main complaint of extra oral pain in the right hemiface, with rapid evolution of three days after extraction.
\end{abstract}


Keywords: Herpes Zoster; Mouth; Oral medicine.

\section{Resumen}

El herpes zoster es una infección viral provocada por la reactivación del virus varicela-zoster, que generalmente afecta a la población anciana. El virus de la varicela, cuando está en estado latente, se localiza en los ganglios del trigémino y cuando se reactiva puede causar lesiones en la cara y vesículas intraorales. Esta enfermedad puede afectar a pacientes inmunosuprimidos con mayor prevalencia y se caracteriza por erupciones maculopapulares distribuidas en la región del nervio afectado, provocando dolor severo, temblores e incluso parestesias. El diagnóstico de herpes zóster suele establecerse a través del cuadro clínico que presenta el paciente y el tratamiento se centra en los síntomas y la causa, optando por el uso de medicamentos antivirales sistémicos y tópicos. En este artículo se reporta el caso de una paciente, leucoderma, sin problemas de salud y con tratamientos inmunosupresores previos, de 56 años, que ingresó en urgencias, teniendo como principal queja el dolor extrabucal en la hemifacial derecha, con rápida evolución de tres días después de la extracción.

Palabras clave: Herpes Zóster; Boca; Medicina oral.

\section{Introdução}

O vírus varicela zoster (VZV) é o agente causal da varicela e as recorrências do vírus são conhecidas como herpes zóster. A infecção primária por VZV é uma doença comum na infância, podendo acontecer também na fase adulta, em populações não vacinadas e é caracterizada por febre, mal-estar e erupção vesicular exantemática envolvendo a face e o tronco, seguida por envolvimento das extremidades. A erupção geralmente progride por estágios de exantema pruriginoso, vesiculação, pustulação e formação de crostas. Em indivíduos imunocompetentes, a infecção é autolimitada e remite em 10-14 dias (McCormick et al., 2016).

A herpes zoster (HZ) é uma infecção viral causada pela reativação do vírus varicela zoster (VZV), que está dormente nos gânglios dos nervos sensoriais. A reativação do vírus latente é caracterizada por um período inicial de dor e sensação de queimação no dermátomo do nervo afetado. Os sintomas usuais são geralmente dor, tremores, parestesia, disestesia e/ou alodinia na área afetada, acompanhada pelo aparecimento de erupções maculopapulares unilaterais no dermátomo afetado. Na fase aguda, as vesículas geralmente aparecem em um lado do corpo; essas lesões geralmente se desenvolvem em lesão ulcerada ou crosta cerca de 7 a 10 dias após a ativação inicial. Muitas vezes a dor continua após as erupções, mesmo meses depois, especialmente nos indivíduos idosos e/ou imunossuprimidos. Este tipo de dor crônica é conhecido como neuralgia pós-herpética (Arora et al., 2015; Bas et al., 2015; Míntz et al., 1992).

O VZV também pode estar dormente nos gânglios trigêmeos e, quando reativado, as lesões podem aparecer na face, lábios, boca ou olhos, ou ao longo de qualquer uma das divisões do nervo trigêmeo. As lesões orais são geralmente unilaterais e se estendem até a linha média e frequentemente se apresentam em conjunto com o envolvimento da pele facial sobreposta. As lesões orais geralmente consistem em pequenas vesículas que se rompem rapidamente para formar úlceras dolorosas superficiais, que se resolvem em 2 à 3 semanas em pacientes imunocompetentes. Outras complicações incluem paralisia motora do nervo facial, neuropatia óptica levando à cegueira e envolvimento das divisões maxilares ou mandibulares do nervo trigêmeo que podem levar à desvitalização dos dentes e reabsorção radicular (McCormick et al., 2016; Mendieta et al., 2005).

Dessa forma, o objetivo do presente trabalho foi relatar um caso clínico de uma paciente atendida no pronto socorro hospitalar com queixas álgicas em face, que havia sido atendida por alguns médicos e não havia sido diagnosticada nem tratada.

\section{Metodologia}

Trata de um estudo retrospectivo, descritivo e observacional no formato de Relato de Caso Clínico (Lüdke \& André, 1986; Koche, 2011), de um paciente que realizou o tratamento durante seu atendimento hospitalar. Os dados epidemiológicos, história da doença e registros fotográficos, foram coletados através do prontuário físico e eletrônico, após a autorização do paciente mediante a assinatura do Termo de Consentimento Livre e Esclarecido (TCLE), seguido as recomendações de ética da Declaração de Helsinque (1984) e também seguido os preceitos da publicação sem a identificação do paciente. 


\section{Caso Clínico}

Paciente feminina, 56 anos, deu entrada no pronto socorro hospitalar, com queixas álgicas em hemiface direita, queixando-se de evolução rápida de três dias. A paciente havia procurado realizado uma exodontia do 36, três dias antes e desencadeou o processo, ela buscou atendimento médico, porém sem sucesso no diagnóstico. A mesma foi então encaminhada ao serviço especializado de cirurgia e traumatologia bucomaxilofacial onde foi avaliada pela equipe. Paciente negava qualquer comorbidades associadas ao quadro geral de saúde, negou alergias, negou tratamentos imunossupressores. Não relatou história prévia de quadro herpético e relatou início espontâneo com prurido, eritema e alodinia na região. A paciente foi avaliada e durante o exame físico, diante da apresentação clínica do quadro de lesões eritematosas com queixa álgica e prurido, de localização polarizada ipsilateralmente em face (Figura 1), foi possível realizar o diagnóstico de HZ.

Figura 1. Aspecto extra oral da paciente na vista frontal. Demonstrando a manifestação unilateral da doença.

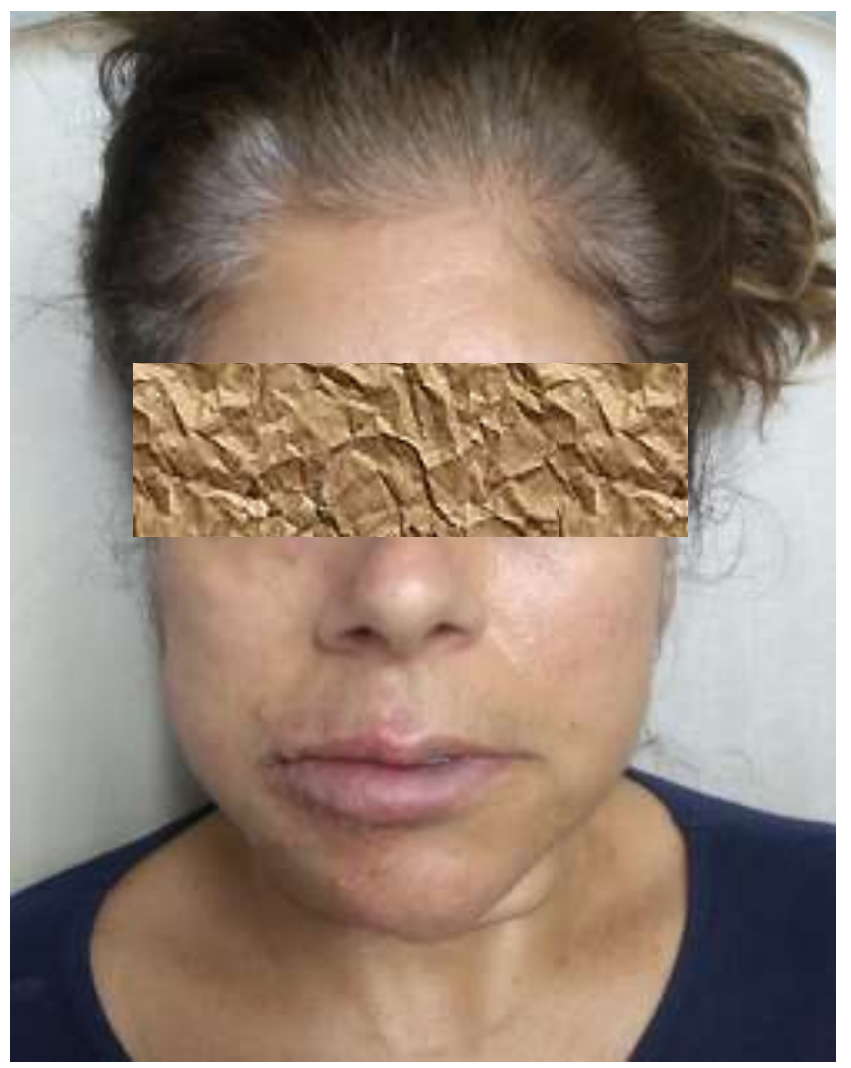

Fonte: Autores.

As lesões ficam claramente estritas a hemiface direita da paciente, respeitando a linha média sagital, sem afetar o lado esquerdo do rosto.

A paciente apresentou no exame físico extraoral (Figura 2) vesículas eritematosas em região orbitária (ramo zigomático), maxilar, labial superior e nasal (ramo bucal) e mandibular e labial inferior e mento (ramo marginal da mandíbula) rigorosamente restritas ao lado direito da face, sem cruzar a linha mediana, condizente com a área de inervação do nervo trigêmeo. 
Figura 2. Vista em $3 / 4$ da face, com lesões estritamente em hemiface Direita.

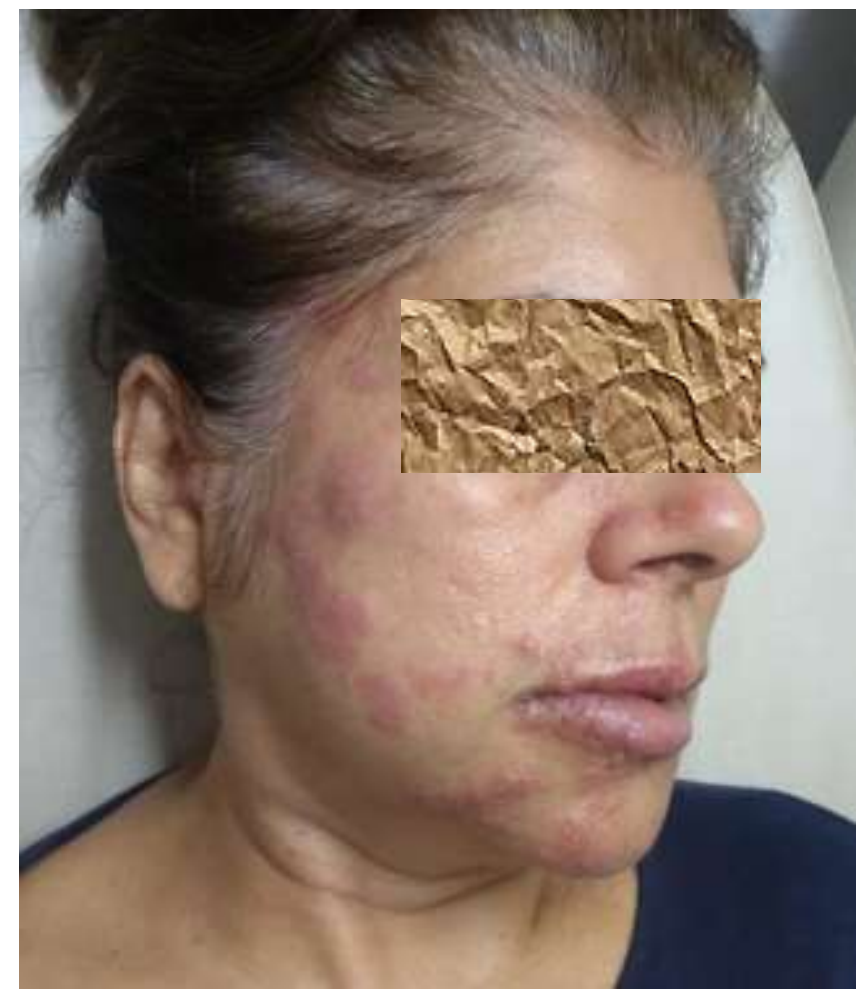

Fonte: Autores.

A Figura 2 demonstra a presença de lesões nos três terços da face direita, com regiões de prurido, eritema e lesões maculopapulares.

À oroscopia foi verificado a presença de lesões também agrupadas, delimitadas e localizadas em região direita de cavidade bucal. Sendo notada a presença de lesões em região de palato duro, mucosa jugal e borda lateral de língua ipsilateralmente (Figura 3).

Figura 3. Aspecto intra oral das lesões unilateralmente, em mucosa palatina, lábio e língua de lateralidade direita.

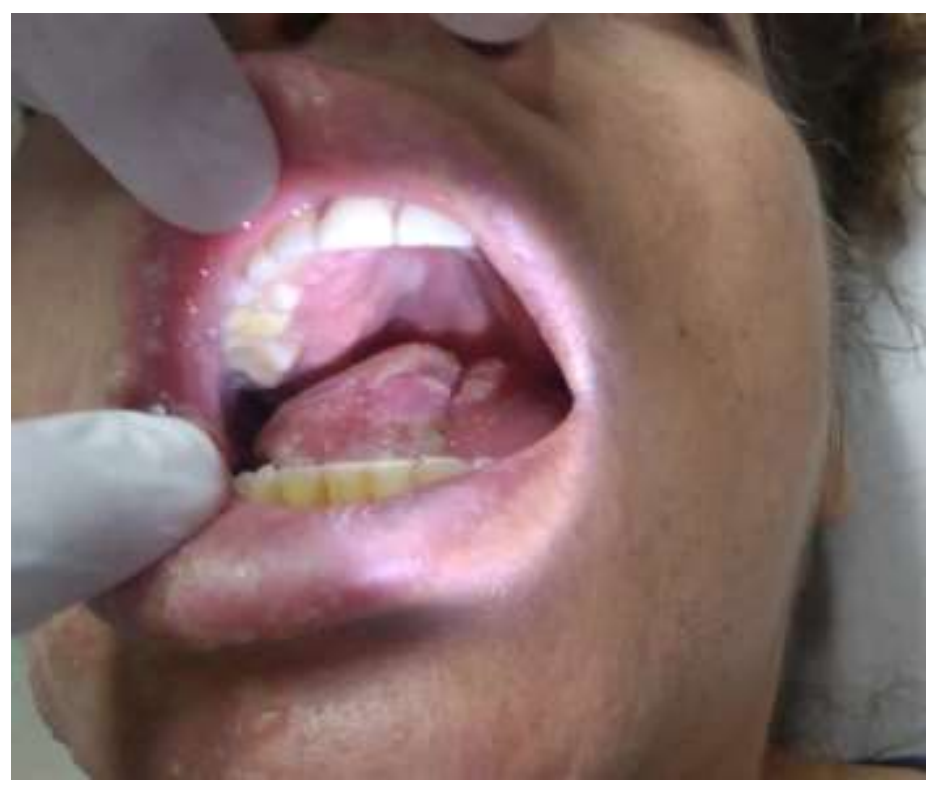

Fonte: Autores. 
Notamos a rigorosa limitação da formação de lesões em região de língua a direita, sendo notável claramente a demarcação da linha sagital mediana pela área afetada e a área hígida. A paciente foi então acalmada e orientada quanto aos cuidados, quanto ao curso natural da doença e tratamento. A paciente foi medicada com analgésicos e iniciado tratamento com aciclovir, recebendo alta hospitalar. A paciente permaneceu em acompanhamento ambulatorial por mais 10 dias onde apresentou completa recuperação das lesões e melhora da alodinia, recebendo alta da especialidade.

\section{Discussão}

Ao contrário da varicela (catapora), o herpes zoster é uma doença esporádica com uma estimativa de incidência ao longo da vida de 10 à 20 por cento, afetando comumente a população idosa (mais de 60 anos) e incomum em idades mais jovens grupo (menos de 15 anos). O aumento da incidência do vírus varicela zoster e reativação pode ser atribuída à diminuição normal da imunidade mediada por células, relacionada à idade. Pacientes com infecção por HIV e certas doenças malignas, pacientes sob corticosteroides crônicos, terapia imunossupressora, quimioterapia e radioterapia apresentam risco aumentado (Priya et al., 2018).

A prevalência desta entidade em pacientes imunodeprimidos pelo HIV é mais elevada do que a população em geral (9.3/1000). A maioria dos casos de herpes zoster em pacientes infectados pelo HIV acomete indivíduos do sexo masculino (62\%), melanodermas (75\%) e com uma média de idade de 39 anos. Cerca de $28 \%$ dos pacientes manifestam complicações associadas ao herpes-zóster e com 12\% desenvolvendo a neuralgia pós-herpética (Blank et al., 2012; Gebo et al., 2005; Hope-Simpson et al., 1965).

As lesões orais do herpes zoster ocorrem quando há o envolvimento do nervo trigêmeo e podem estar presentes na mucosa móvel ou aderida. As lesões estendem-se à linha média e estão presentes, frequentemente, em conjunto com o acometimento da pele que recobre o quadrante afetado (Pivovar et al., 2013). A paciente deste relato de caso exibia as lesões na pele da hemiface direita, ou seja, em lábio, mucosa jugal, borda lateral de língua e palato do lado direito.

O diagnóstico do herpes zoster geralmente é estabelecido por meio do quadro clínico. Os elementos importantes para o estabelecimento do diagnóstico por observação incluem: (I) pródromo sensorial doloroso ou anormal (nem sempre presente), (II) distribuição em um dermátomo, (III) vesículas agrupadas (no entanto, em alguns casos, apenas será observado pápulas), (IV) múltiplos locais preenchendo o dermátomo, especialmente onde as divisões do nervo sensorial estão representadas, (V) a falta de história de uma erupção semelhante na mesma distribuição (para descartar herpes simples zosteriforme recorrente) e (VI) dor e alodinia na área da erupção (Pivovar et al., 2013). O presente relato apresenta somente pródomo sensorial doloroso, vesículas agrupadas, distribuição em um dermátomo e múltiplas regiões de um mesmo tronco nervoso sensorial (Thompson et al., 2008).

$\mathrm{O}$ tratamento do VZV reativado é direcionado à causa e aos sintomas. Terapia antiviral sistêmica, como aciclovir, famciclovir ou valaciclovir têm se mostrado aptos a reduzir a severidade e a duração da infecção por VZV, e estes medicamentos são considerados os pilares da terapia do herpes zoster. Os agentes antivirais tópicos são ineficazes para o tratamento do herpeszóster e não são recomendados (McCormick et al., 2016). A escolha do tratamento dependerá da severidade da dor. A paciente não relatou história de manifestação da doença pregressa, sendo, portanto, a primeira reativação do vírus após a fase adulta. O tratamento utilizado para tratamento desta paciente foi a prescrição do antiviral aciclovir.

Em geral, os analgésicos narcóticos, os antidepressivos tricíclicos, os medicamentos anti-inflamatórios não esteroides e o acetaminofen podem ser adicionados. No entanto, os riscos associados ao uso de corticosteroides devem ser avaliados cuidadosamente (Dworkin et al., 2007).

Uma possível complicação na infecção por HZ no nervo trigêmeo ou facial maxilar é o desenvolvimento de uma paralisia craniana e periférica, como a Síndrome de Ramsay-Hunt, na qual o paciente desenvolve paralisia de Bell, vesículas dentro do ouvido externo e perda sensibilidade nos dois terços anteriores da língua (Raj et al., 2017). Apesar de as lesões 
acometerem a pele da face, a paciente não foi enquadrada como portadora da síndrome de Ramsay Hunt (também conhecida como herpes zoster óptica), pois não exibia paralisia facial periférica (Wadhawan et al., 2015).

Foi demonstrado que uma vacina viva-atenuada com VZV possui eficácia contínua por 3 anos após a vacinação. A vacina contra herpes zóster tem a mesma composição da vacina da varicela, dada na infância, porém com conteúdo do agente imunizante cerca de 14 vezes maior. Um grande estudo randomizado, controlado com mais de 30.000 adultos, com finalidade de avaliar a eficácia e segurança da vacina indicou uma redução no risco de herpes zóster em $51 \%$ e no risco de nevralgia pósherpética em 67\%. As maiores respostas imunológicas são observadas após seis semanas da aplicação da vacina. Naquelas pessoas que, mesmo após vacinação, desenvolveram herpes-zóster, a vacina reduziu significativamente a dor relacionada ao herpes-zóster em comparação ao placebo. No período de acompanhamento de 6 meses, houve redução de $22 \%$ na pontuação de gravidade da dor (Oxman et al., 2005).

Portanto, é extremamente importante que esses sinais e sintomas clínicos sejam avaliados e reconhecidos pela classe odontológica e médica, visto que a $\mathrm{HZ}$ é conhecida pelos seus sinais sistêmicos, porém sua apresentação em face é menos difundida, e consequentemente menos diagnosticada. A importância do diagnóstico precoce desse tipo de lesões, é poder iniciar o tratamento terapêutico nas primeiras fases das lesões, atenuando a dor e o prurido, melhorando a sintomatologia, a duração da manifestação e a qualidade de vida dos pacientes acometidos.

\section{Conclusão}

O cirurgião-dentista bem como a comunidade médica que atende a população deve estar familiarizado e apto a tratar este tipo de ocorrência clínica. O diagnóstico é realizado clinicamente, sem necessidade de exames complementares, podendo ser facilmente identificado e tratado imediatamente para diminuir o seu tempo de manifestação.

\section{Referências}

Arora, P. C., Manchanda, A. S., Narang, R. S., \& Arora, A. (2015). Mandibular osteonecrosis and teeth exfoliation after herpes zoster infection in an HIVinflicted individual. Journal of Indian Academy of Oral Medicine and Radiology, 27(1), 101.

Baş, B., Özden, B., Ozdemir, M., \& Yüksel, E. P. (2015). Herpes zoster ophthalmicus reactivation following maxillary sinus lift operation: A case report. European journal of oral implantology, 8(2).

Blank, L. J., Polydefkis, M. J., Moore, R. D., \& Gebo, K. A. (2012). Herpes zoster among persons living with HIV in the current ART era. Journal of acquired immune deficiency syndromes (1999), 61(2), 203.

Dworkin, R. H., Johnson, R. W., Breuer, J., Gnann, J. W., Levin, M. J., Backonja, M., \& Whitley, R. J. (2007). Recommendations for the management of herpes zoster. Clinical infectious diseases, 44(Supplement_1), S1-S26.

Gebo, K. A., Kalyani, R., Moore, R. D., \& Polydefkis, M. J. (2005). The incidence of, risk factors for, and sequelae of herpes zoster among HIV patients in the highly active antiretroviral therapy era. JAIDS Journal of Acquired Immune Deficiency Syndromes, 40(2), $169-174$.

Hope-Simpson, R. E. (1965). The nature of herpes zoster: a long-term study and a new hypothesis. Proc R Soc Med., 58, 9-20.

Koche, J. C. (2011). Fundamentos de metodologia científica. Petrópolis: Vozes.

Lüdke, M., \& André, M. (1986). Pesquisa em educação: abordagens qualitativas. E.P.U.

McCormick, A. P., Kanas, R. J., Orton, M., \& Rice, T. (2016). Unusual Necrosis of the Lower Lip Following a Varicella Zoster Recurrence. Int J Oral Dent Health, 2(1), 2469-5734.

Mendieta, C., Miranda, J., Brunet, L., Gargallo, J., \& Berini, L. (2005). Alveolar bone necrosis and tooth exfoliation following herpes zoster infection: a review of the literature and case report. Journal of periodontology, 76(1), 148-153.

Mintz, S. M., \& Anavi, Y. (1992). Maxillary osteomyelitis and spontaneous tooth exfoliation after herpes zoster. Oral surgery, oral medicine, oral pathology, $73(6), 664-666$.

Oxman, M. N., Levin, M. J., Johnson, G. R., Schmader, K. E., Straus, S. E., Gelb, L. D., \& Silber, J. L. (2005). A vaccine to prevent herpes zoster and postherpetic neuralgia in older adults. New England Journal of Medicine, 352(22), 2271-2284. 
Research, Society and Development, v. 10, n. 2, e31610212617, 2021

(CC BY 4.0) | ISSN 2525-3409 | DOI: http://dx.doi.org/10.33448/rsd-v10i2.12617

Pivovar, L., Cossul, M. F., de Melo, J. R., Gil, F. B. D., \& de Lima, A. A. S. (2013). Herpes-zóster com manifestação bucal em paciente imunossuprimido: relato de caso. Archives of Oral Research, 9(2).

Priya, P., \& Mukhopadhyaya, I. (2018). A rare case of herpes zoster of mandibular division, trigeminal nerve (left) in an elderly lady involving extraorally and intraorally both. Guident, 11(12).

Raj, S. S., Verma, P., Mahajan, P., \& Puri, A. Herpes zoster infection of the face: A case report with review of literature. J Indian Acad Oral Med Radiol 2017;29:159-61.

Thompson, D. S., Bain, B., \& East-Innis, A. (2008). The prevalence of mucocutaneous disorders among HIV-positive patients attending: an out-patient clinic in Kingston, Jamaica. West Indian Med J, 57(1), 54-57.

Wadhawan, R., Luthra, K., Reddy, Y., Singh, M., Jha, J., \& Solanki, G. (2015). Herpes zoster of right maxillary division of trigeminal nerve along with oral manifestations in a 46 year old male. Int J Adv Biol Res, 5, 281-4. 